\title{
Original Article \\ One year outcome of Subacromial Methylprednisolone Injection and Psychotherapy for Subacromial Impingement Syndrome
}

\author{
Lakhey S; Manandhar RR
}

\begin{abstract}
BACKGROUND: Subacromial impingement syndrome is a common cause of pain in the shoulder region. When analgesics and physiotherapy are not helpful in relieving the patient's shoulder pain, subacromial methylprednisolone injection is given. The aim of this prospective study was to determine the one year clinical outcome of subacromial injections of methylprednisolone and physiotherapy in patients with subacromial impingement syndrome.

METHODS: The pain of thirty shoulders in twenty nine patients characteristic of subacromial impingement syndrome was assessed by Visual Analogue Scale (VAS) scores of 0 to 10, and the overall clinical and functional assessment was done by Constant Murley score. Each shoulder received methylprednisolone injection in the sub-acromial space by the posterior approach. The subacromial injections were repeated at two to three weekly intervals (a maximum of three injections) until the pain subsided to 2 or less in the VAS. This was followed by physiotherapy exercises. Treatment Outcome at final follow-up of one year was measured using VAS and Constant Murley Score.
\end{abstract}

RESULTS: Pain before starting the injections was a mean of 7.87 in the VAS (range: 5-10 ). At the end of follow-up, it was a mean of 1.27 (range: 0 to 5). The Constant Murley Score was a mean of 30.83 (range: 6-49) before the start of injections. At the end of follow-up, it was a mean of 84.87(range: 70-96).

CONCLUSION: Subacromial methylprednisolone injections followed by physiotherapy exercises can provide statistically and clinically satisfactory pain relief and improvement of shoulder function at one year follow up in $96.7 \%$ patients with subacromial impingement syndrome.

KEY WORDS: subacromial impingement syndrome, Constant Murley score, subacromial methylprednisolone injection.

\section{INTRODUCTION}

Subacromial impingement syndrome is a common cause of pain in the shoulder region ${ }^{1}$. Various intrinsic (intratendinous) or extrinsic (extratendinous) factors can be responsible for the syndrome ${ }^{2}$. Rotator cuff muscle weakness, overuse and degeneration of the tendons are among the intrinsic causes while some of the extrinsic causes include the shape of the acromian process, degeneration of the $\mathrm{AC}$ joint, impingement by $\mathrm{CA}$ ligament, os acromiale and coracoid process. Sometimes in the younger individual, glenohumeral instability may be a secondary cause of sub-acromial impingement syndrome. When analgesics and physiotherapy are not helpful in relieving the patient's shoulder pain, subacromial corticosteroid injection is given ${ }^{3}$. The aim of this prospective study was to determine the one year clinical outcome of subacromial injections of methylprednisolone and physiotherapy in patients with subacromial impingement syndrome.

\section{MATERIALS AND METHODS}

Twenty nine patients with thirty painful shoulders characteristic of subacromial impingement syndrome seen by the two authors in four clinics from January 2007 to April 2009 were included in the study if they met the following criteria: 1.A diagnosis of subacromial impingement syndrome was made on the basis of history, clinical examination ${ }^{4}$ and if a positive impingement sign was demonstrated as described by Hawkins and Kennedy ${ }^{5}$. The patients presented with pain on anterolateral aspect of shoulder which was referred to the deltoid insertion. On clinical examination, Jobe's test and Speed's test were positive along with decrease in active and passive range of motion of the shoulder. Any attempt to move the shoulder joint beyond this range was painful. 2.Pain did not subside with a week of NSAIDS ( Naproxen or Diclofenac sodium) . 
NEPAL ORTHOPAEDIC ASSOCIATION JOURNAL (NOAJ) VOLUME1, NUMBER ONE, JANUARY 2010

ONE YEAR OUTCOME OF SUBACROMIAL METHYLPREDNISOLONE INJECTIONANDPSYCHOTHERAPY FOR UBACROMIAL IMPINGEMENT SYNDROME, Lakhey S; Manandhar RR

Plain x-rays of the shoulder AP, lateral and axillary views were taken. Features suggestive of glenohumeral instability, degenerative joint disease, cervical radiculitis, calcific tendinitis, adhesive capsulitis, isolated AC joint arthritis ${ }^{2}$, unfused acromial epiphysis ${ }^{6}$ and suprascapular nerve compression were excluded from the study. Similarly, patients with clinical and routine $x$-ray pictures of massive rotator cuff tears ${ }^{7}$ were excluded from the study as were patients $<40$ years of age as they could have subtle glenohumeral instability ${ }^{8}$ contributing to subacromial impingement syndrome.

The shoulder pain was assessed by Visual Analogue Scale (VAS) scores of 0 to 10 , and overall clinical and function of the involved shoulder were assessed by Constant Murley Score'. Each shoulder received $4 \mathrm{ml}$ of plain $1 \%$ xylocaine mixed with $2 \mathrm{ml}$ of methyl prednisolone (containing $80 \mathrm{mg}$ ) injections. A $10 \mathrm{cc}$ syringe with $5 \mathrm{~cm}$ long, $21 \mathrm{~g}$ needle was used to instill the injection in the sub-acromial space by the posterior approach. Inj. Diclofenac $75 \mathrm{mg}$ was given IM in the gluteal region followed by oral analgesics (codeine 10 $\mathrm{mg}$. and paracetamol $500 \mathrm{mg}$. combination tablets) three times a day for three days. The subacromial injections were repeated at two to three weekly intervals (a maximum of three injections) until the pain subsided to 2 or less in the VAS. This was followed by physiotherapy exercises. In one patient, it did not go below 5 even after 3 injections. She was advised surgery, but she opted for physiotherapy exercises and oral analgesics.

Rehabilitaion was undertaken in 3 basic phases as defined by Wirth et al. ${ }^{10}$

1. Pain was controlled

2. Range of motion of the shoulder joint was restored

3. Rotator cuff muscle strengthening was developed.

Treatment Outcome at final follow-up of one year was measured using VAS and Constant Murley ${ }^{9}$ score.

Constant and Murley score ${ }^{9}$ provides an overall clinical and functional assessment of the shoulder irrespective of the diagnostic or radiological abnormalities caused by disease or injury. It is accurately reproducible by different observers and sufficiently sensitive to reveal even small changes in function. It is a100 point scoring system based on a number of individual parameters. (Table-1)

Table-1: Constant Murley Scoring for

Individual Parameters

\begin{tabular}{lll}
\hline 1. & Pain & 15 \\
2. & Activities of daily living & 20 \\
3. & Range of motion & 40 \\
4. & Power & 25 \\
& Total & 100 \\
\hline
\end{tabular}

The subjective parameters, which comprise of 35 points, assess the degree of pain the patient experiences and the ability to perform normal tasks of activities of daily living. The objective parameters, which comprise of 65 points, assess active range of motion of the shoulder that allows placement of upper limb in functionally relevant position and the power in the shoulder joint.

Data entry was done in Microsoft Excel 2007 version and analysis was done using SPSS version 16 programme. Paired t-test was applied to assess the statistical significance of pain and shoulder function before and after treatment.

\section{RESULTS}

Twenty nine patients with thirty shoulders (15 men and 14 women) with a mean age of 54.7 years (range 42 to 72 years; std. deviation: 8.699 ) who met the criteria were included in the study. The mean duration of symptoms before the injection was 2.07 months (range 1 to 6 months; std. deviation: 1.172). The right shoulder was involved in 18 patients and left shoulder in 12 patients. The shoulder pain was of spontaneous onset in 21 patients whereas in 8 patients, they attributed it to an incident of strain/ minor injury.

The patients were followed up for a minimum of one year. Pain before starting the injections was a mean of 7.87 in the VAS (range: 5-10 ). At the end of follow-up, it was a mean of 1.27 (range: 0 to 5). The Constant Murley Score was a mean of 30.83 (range: 6-49) before the start of injections. At the end of follow-up, 
NEPAL ORTHOPAEDIC ASSOCIATION JOURNAL (NOAJ) VOLUME1, NUMBER ONE, JANUARY 2010
ONE YEAR OUTCOME OF SUBACROMIAL METHYLPREDNISOLONE INJECTIONANDPSYCHOTHERAPY FOR UBACROMIAL IMPINGEMENT SYNDROME, Lakhey S;

Manandhar RR it was a mean of 84.87(range: $70-96)$. There were no complications of the procedure.

Table 2: Comparative Pain, Clinical and Functional Assessment of Shoulder before and after Treatment

\begin{tabular}{cccc}
\hline & $\begin{array}{c}\text { Pre-injection } \\
\text { (mean } \\
\text { standard } \\
\text { deviation) }\end{array}$ & $\begin{array}{c}\text { One year } \\
\text { follow } \\
\text { up (mean } \\
\text { standard } \\
\text { deviation) } \\
1.27 \\
(1.048)\end{array}$ & $\begin{array}{c}\text { p-value } \\
\text { (paired-T } \\
\text { test applied) }\end{array}$ \\
Pain in & $7.87(1.306)$ & 0.000 \\
VAS & & $84.87(5.513)$ & 0.000 \\
Constant & 30.83 & & \\
Murley & $(10.313)$ & & \\
Score & & & \\
\hline
\end{tabular}

\section{DISCUSSION}

Subacromial impingement syndrome is caused by narrowing of the sub-acromial space with secondary impingement of the bursal surface of rotator cuff on the undersurface of the acromion ${ }^{2,11,12,13,14,15}$.

The objective of treatment is reduction of pain and improvement of shoulder function. When NSAIDs and physiotherapy are unable to control the pain, subacromial steroid injection is given. Subacromial injections can be given by anterior, posterior or lateral approach. Among the steroid injections, depot formulations are chosen for subacromial injections. Depot formulation tend to remain at the injection site for a long period of time and display mainly local effects as compared to watersoluble formulations like Dexamethasone which diffuse rapidly from the injected site and exert mainly systemic effects $^{16}$. The choice of depot formulation depends on a variety of factors including availability, cost and pharamacokinetics of the agent ${ }^{16}$. Methylprednisolone and Triamcinolone are the depot formulation commonly available in the market. The reported ranges for duration of action vary between different corticosteroids and sometimes, for the same corticosterod. Accuracy of needle placement can affect the outcome of soft tissue disorders. Only 30 to 80 percent of subacromial injections are reported to reach the subacromial bursa or space when a blind injection technique is used ${ }^{17}$. Use of sonography could increase the accuracy of injection and thereby improve outcome ${ }^{18}$. By using 2 to 3 weekly subacromial methylprednisolone injections up to a maximum of 3 injections, we believe, the inaccuracy of blind subacromial injections was taken care of.

Outcome periods of local steroid injections are categorised as short term ( 6 weeks ), intermediate term ( 6 weeks to 6 months ) and long term ( more than 6 months $)^{16}$. This study is a one year follow up study of treatment of subacromial methylprednisolone injection and physiotherapy for subacromial impingement syndrome, and therefore, can be termed as long term study.

28 patients with 29 shoulders were satisfied with the level of pain control and improvement of shoulder function achieved by subacromial methylprednisolone injections followed by physiotherapy exercises. One patient did not achieve satisfactory pain control ( VAS of 5 after 3 injections) with the three subacromial methylprednisolone injections and was advised surgery. She didn't want surgery and opted for physiotherapy exercises. The pain did not decrease at the end of one year. However at the end of eighteen months follow up, she had no pain and could carry out all her activities of daily living without any difficulties. A patient with bilateral subacromial impingement syndrome, who was doing well at end of one year follow up with good pain control and shoulder function, had recurrence of pain at eighteen months follow up. Two repeat subacromial methylprednisolone injections for each shoulder did not help relieve her pain and she was advised surgery. The patient satisfaction rate of subacromial methylprednisolone injection for subacromial impingement syndrome at the end of one year (long term outcome) was $96.7 \%$ (29 of 30 shoulders). However, at eighteen months follow-up, it was $93.3 \%$ ( 28 of 30 shoulders).

Literature search revealed satisfactory results with conservative treatment including NSAIDs and physiotherapy exercises are $67 \%$ in one study ${ }^{19}$. In a recent study based on conservative programme including NSAIDs, physiotherapy and subacromial steroid injections, an overall success rate of $70 \%$ was obtained in treating patients with subacromial impingement syndrome ${ }^{20}$. 
NEPAL ORTHOPAEDIC ASSOCIATION JOURNAL (NOAJ) VOLUME1, NUMBER ONE, JANUARY 2010

ONE YEAR OUTCOME OF SUBACROMIAL METHYLPREDNISOLONE INJECTIONANDPSYCHOTHERAPY FOR UBACROMIAL IMPINGEMENT SYNDROME, Lakhey S;

Manandhar RR

There were certain limitations in our study: there were only 30 shoulders included in the study and it involved an only one year follow up period.

\section{CONCLUSION}

Subacromial methylprednisolone injections given by trained orthopaedic surgeons followed by physiotherapy exercises can provide statistically and clinically satisfactory pain relief and improvement of shoulder function in a one year follow up of $96.7 \%$ patients with subacromial impingement syndrome. However, a study involving more patients followed up for longer term periods could more accurately conclude the long term outcome of subacromial methylprednisolone injections in these patients.

(Acknowledgements: Mr. Umesh Aryal, Statistician, KMCTH. Faculty Members, Dept. of Ortho., KMCTH.)

\section{REFERENCES}

1. Neer, C.S., II: Anterior Acromioplasty for the Chronic Impingement Syndrome in the Shoulder: a Preliminary Report. JBJS, 54-A: 41-50. 1972.

2. Bigliani, L.U.; and Levine, W.N. : Current Concepts Review- Subacromial Impingement Syndrome. JBJS, 79-A: 1854-68. 1997.

3. Blair, B.; Rokito, A.S.; Cuomo, F.; Jarolem, K.; and Zuckerman, J.D.: Efficacy of Corticosteroids for Subacromial Impingement Syndrome. JBJS, 78-A: 1685-9. 1996.

4. Tytherleigh-Strong, G.; Hirahara, A.; and Miniaci, A.: Rotatotor Cuff Disease. Current Opinion in Rheumatology. 13: 135-145. 2001.

5. Hawkins, R.J.; and Kennedy, J.C.: Impingement Syndrome in Atheletes. Am. J. Sports Med., 8: 151-158. 1980.

6. Edelson, J.G.; Zuckerman, J; and Hershkovitz, I.: Os acromiale: Anatomy and Surgical Implications. JBJS, 75B(4): 551-554. 1992.

7. Kaneko, K.; DeMony, E.H.; and Brunet, M.E.: Massive Rotator Cuff Tears: Screening by Routine Radiographs. Clin. Imag., 19:8. 1995.

8. Jobe, F.W.; Kvitne, R.S.; and Giangarra, C.E.: Shoulder Pain in the Overhand or Throwing Athlete. The Relationship of Anterior Instability and Rotator Cuff Impingement. Orthop. Rev., 18: 963-975. 1989.
9. Constant, C.R,; and Murley, A.H.G.: A Clinical Method of Functional Assessment of Shoulder. Clin. Orthop. and Rel. Research., 214: 160-164. Jan. 1987.

10. Wirth, M.A.; Basamania, C.; and Rockwood, C.A. Jr.: Non-operative Management of Full-thickness Tears of Rotator Cuff. Orthop. Clin. North Am., 28: 59-69. 1997.

11. Cofield, R. H.: Current Concept Review. Rotator Cuff Disease of the Shoulder. JBJS, 67-A: 974-979. 1985.

12. Hawkins, R. J.; and Brock, R.M.: Anterior Acromioplasty: Early Results for Impingement with Intact Rotator Cuffs. Orthop. Trans. 3: 274. 1979.

13. Jackson, D.W.: Chronic Rotator Cuff Impingement in the throwing Athlete. Am. J. Sports Med. 4: 231-240. 1976.

14. Matsen, F.A.III; and Arntz, C.T.: Subacomial Impingement in the Shoulder, pp. 623-646. Edited by C.A. Rockwood, Jr., and F.A.Matsen,III. Philedelphia, W.B. Saunders, 1990.

15. White, R.H.; Paull, D.M.; and Fleming, K.W.: Rotator Cuff Tendinitis: Comparision of Subacromial Injection of Long Acting Corticosteroid versus Oral Indomethacin Therapy. J. Rheumatol. 13: 608-613. 1986.

16. Cole, B.J.; and Schumacher Jr, H.R.: Injectable Corticosteroids in Modern Practice. J Am Acad Orthop Surg., 13(1): 37-46. 2005.

17. Gruson, K.I.; Ruchelsman, D.E.; and Zuckerman, J.D.: Subacromial Corticosteroid Injections. J Shoulder Elbow Surg., 17( suppl): 118-305. 2008.

18. Naredo, E.; Cabero, F.; Baneyto, P.; et al: A Randomised Comparative Study of Short Term Response to Blind Injection versus Sonographic-guided Injection of Local Corticosteroids in Patients with Painful Shoulder. J. Rheumatol. 31: 308-314. 2004.

19. Morrison, D.S.; Frogameni, A.D.; and Woodworth, P.: Non-operative Treatment of Subacromial Impingement Syndrome. JBJS, 79-A: 732-737. May 1997.

20. Johnson, D.H.; and Pedowitz, R.A.: Practical Orthopaedics and Sports Medicine and Arthroscopy. pg.165. Lippincott William and Wilkin, 2007.

Dr.Shishir Lakhey,

Dept. of Orthopaedics

Kathmandu Medical College

Sinamangal, Kathmandu, Nepal

E-mail: slakhey64@yahoo.com 